De-wei Pan

Cheng-xin Lin

Zhi-jie Liu

De-ping Sun

http://dx.doi.org/10.21278/brod67307

ISSN 0007-215X

eISSN 1845-5859

\title{
CALCULATION ON THE UPRIGHTING PROCESS OF A CAPSIZED SHIP
}

UDC 629.5.015.144:629.5.015.152:519.6

Original scientific paper

\begin{abstract}
Summary
The processes of marine salvage require firstly the uprighting of the capsized ship, essentially bringing the deck to point up. Analysis and computation are the keys for the success in the application of the design schemes. Up to date, there are few researches on calculation methods for uprighting process of capsized ships at China and abroad. Researches about the effect of flooding quantity and the variation of the longitudinal strength during the uprighting process of capsized and damaged ships are even rarer. In this paper, hydromechanical equations to describe the effect of flooding are established and a calculation method for the longitudinal strength is introduced with reference to the hydrostatic theory for ships. Three typical uprighting processes are summarized according to the methods of treatment of damaged compartment. The stability of the inverted ship is calculated and analyzed using the General Hydrostatics software(GHS). Reserve buoyancy, shear forces, bending moments and torques are calculated in nine positions along the ship.
\end{abstract}

Key words: $\quad$ hydrostatic; capsize; damaged ship; uprighting 


\section{Introduction}

In traditional marine salvage, empirical methods are applied to define an uprighting program, analyzing only some of the typical conditions of the capsized ship. The calculation process is complex and time consuming, while incorrect calculations and large errors can cause the occurrence of serious accidents [1].

Ship stability and floatation must be determined before uprighting. The position of a floating ship is determined by heeling angle, trim, and draft. Zhao [2] proposed a solution of equilibrium equations of damaged ship using an optimistic algorithm based on Vlasov parameters. Lin et al. [3] used a damaged ship's insubmersibility and the Green formula to determine its floating condition. Li [4] studied the floating condition, stability, and insubmersibility of a lumber carrier, and completed a simulation.

Another factor affecting the stability of the ship and the difficulty of salvage is the presence of free liquids. Couser [5] obtained the static effect of fluid on a half-filled, prismatic tank with rectangular cross-section, which used to validate the software program called Hydromax. The ratio between the tank breadth and its height $(\mathrm{b} / \mathrm{h})$ was also studied, providing the free surface effect. Guo et al. [6] proposed an easy optimum method to determine the free surface effect, providing three examples for a spherical tank and showing the efficacy of the method and its possible application.

The flooding of a damaged compartment increases the weight of the ship and affects its floatation and stability. Ruponen [7] divided the flooding process into three main phases, and consequently studied the effects of ventilation ducts and the strength of the non-watertight subdivision. Vermee et al. [8] studied the sudden ingress of water in the transient stages by theoretical calculation and experiments, applying a longitudinal subdivision to avoid the rapid capsizing phenomenon. Mironiuk [9] studied the accidents of Polish warships in 1985-2004, calculating the quantity of water flooded to the interior compartment and applying the estimating flooding time method.

Longitudinal strength, transverse strength and local strength are commonly used to assess the strength of a ship. Longitudinal strength, in particular, is the most important parameter to ensure the safety of a ship structure [10]. Ivanov [11] proposed an analytical approximate method to calculate shear forces and bending moments of still water, which are analytically presented in dimensionless format, in order to compare results obtained for ships of different sizes. Dubravka et al. [12] established a mathematical model to determine transversal forces and bending moments, and the errors between calculated results and the results from the book were analyzed. Khan and Das [13] derived the bending moments based on a stress-strain relationship, and the residual strength of one tanker and two bulk carriers were determined using Smith's method. Paik et al. [14] studied the ultimate strength characteristics of ship hulls under torsion with large hatch openings. Wang et al. [15] derived the method for the calculation of the residual strength of a hull girder for a broad spectrum of accidents, independently from the principal dimensions of a ship, with a great advantage in cases of emergency or salvage operation.

According to statistics, calculation with simulation software is more than twice as faster as traditional calculations, and is also much more accurate [16]. Liu et al. [17] developed a software program via Microsoft Visual Basic 6.0, Microsoft Excel 2000, and Microsoft Access 2000, which can calculate the weight of a ship in water and help design the configuration scheme of pontoons. Liu et al. [18] devised software that can help design the layout scheme of a worksite for salvage engineering. Liu et al. [19] discussed the feasibility of a PDA (personal digital assistant) application in rescue salvage and diving. Huang et al. [20] designed a computer program to speed up salvage computation. These programs have significant theoretical and functional value for salvage projects. 
Table 1 Table of symbols

\begin{tabular}{|c|c|c|c|c|c|}
\hline Characteristic & Abbreviation & Unit & Characteristic & Abbreviation & Unit \\
\hline Waterline & WL & & Gravity of ship & $W$ & $\mathrm{~N}$ \\
\hline Reserve buoyancy & $\Delta_{R B}$ & $\mathrm{~N}$ & Righting force & $F$ & $\mathrm{~N}$ \\
\hline $\begin{array}{l}\text { Total buoyancy force of all } \\
\text { compartments both above and } \\
\text { below the waterplane that are } \\
\text { watertight or can be made } \\
\text { watertight to withstand the } \\
\text { external hydrostatic pressure }\end{array}$ & $\Delta_{0}$ & $\mathrm{~N}$ & $\begin{array}{l}\text { Moment of inertia of the liquid } \\
\text { surface with respect to the } \\
\text { barycentric axis (of the free } \\
\text { surface) parallel to the axis of } \\
\text { heeling }\end{array}$ & $I_{B}$ & $\mathrm{~m}^{4}$ \\
\hline Displacement of intact ship & $\Delta$ & $\mathrm{N}$ & Area of the damage opening & A & $\mathrm{m}^{2}$ \\
\hline Mass density(water) & $\rho$ & $\mathrm{g} / \mathrm{m}^{3}$ & Position of breach & Area A & \\
\hline $\begin{array}{lll}\text { Displacement } & \text { volume } & \text { of } \\
\text { flooded water } & & \end{array}$ & $\nabla_{\text {fiv }}$ & $\mathrm{m}^{3}$ & $\begin{array}{l}\text { Three components of the } \\
\text { righting force moment }\end{array}$ & $M_{X F}, M_{Y F}, M_{Z F}$ & N.m \\
\hline $\begin{array}{l}\text { Buoyancy force of salvage } \\
\text { pontoons }\end{array}$ & $\Delta_{S P}$ & $\mathrm{~N}$ & $\begin{array}{l}\text { Three components of the } \\
\text { moment of buoyancy force }\end{array}$ & $M_{X B}, M_{Y B}, M_{Z B}$ & \\
\hline Righting arm & $\overline{G Z}$ & $\mathrm{~m}$ & Flow coefficient & $\mu$ & \\
\hline Heeling angle & $\phi$ & $\circ$ & Center of gravity of intact ship & $G$ & \\
\hline Trim & $\theta$ & $\circ$ & Buoyancy center of intact ship & $B$ & \\
\hline $\begin{array}{l}\text { Coordinates of center of gravity } \\
\text { of intact ship }\end{array}$ & $\begin{array}{c}X_{C G}, Y_{C G} \\
\quad Z_{C G}\end{array}$ & & $\begin{array}{l}\text { Coordinates of the righting } \\
\text { force functional point }\end{array}$ & $X_{F}, Y_{F}, Z_{F}$ & \\
\hline $\begin{array}{l}\text { Coordinates of buoyancy center } \\
\text { of intact ship }\end{array}$ & $\begin{array}{c}X_{C B}, Y_{C B} \\
Z_{C B}\end{array}$ & & $\begin{array}{l}\text { Inflow quantity of the damaged } \\
\text { compartment of the } i \text {-th value }\end{array}$ & $q_{i}$ & $\mathrm{~m}^{3}$ \\
\hline Fixed coordinate system & $O_{1} \xi \eta \zeta$ & & $\begin{array}{l}\text { Righting force per unit length at } \\
\text { section } \mathrm{x}\end{array}$ & $f(x)$ & $\mathrm{N}$ \\
\hline Ship fixed coordinate system & Oxyz & & Initial flooding quantity & $\nabla_{I}$ & $\mathrm{~m}^{3}$ \\
\hline $\begin{array}{l}\text { Unit vector of the fixed } \\
\text { coordinate system }\end{array}$ & $\vec{i}, \vec{j}, \vec{k}$ & & $\begin{array}{l}\text { Three components of the } \\
\text { moment of ship weight }\end{array}$ & $M_{X G}, M_{Y G}, M_{Z G}$ & \\
\hline Righting moment & $M_{S}$ & N.m & Shear force at section $\mathrm{x}$ & $N(x)$ & $\mathrm{N}$ \\
\hline $\begin{array}{l}\text { Waterline of ship in neutral } \\
\text { position }\end{array}$ & $\mathrm{W}_{0} \mathrm{~L}_{0}$ & & $\begin{array}{l}\text { Total volume of damaged } \\
\text { compartment of the i-th value }\end{array}$ & $\nabla_{i}$ & $\mathrm{~m}^{3}$ \\
\hline $\begin{array}{l}\text { New waterline of ship in the } \\
\text { neutral position }\end{array}$ & $\mathrm{W}_{1} \mathrm{~L}_{1}$ & & $\begin{array}{l}\text { Center of gravity of damaged } \\
\text { compartments }\end{array}$ & $x_{C G}, y_{C G}, z_{C G}$ & \\
\hline $\begin{array}{l}\text { Waterline of compartment of } \\
\text { ship in neutral position }\end{array}$ & $\mathrm{W}_{\mathrm{c} 0} \mathrm{~L}_{\mathrm{c} 0}$ & & $\begin{array}{l}\text { Longitudinal load per unit } \\
\text { length at section } \mathrm{x}\end{array}$ & $q(x)$ & $\mathrm{N}$ \\
\hline New waterline of compartment & $\mathrm{W}_{\mathrm{c} 1} \mathrm{~L}_{\mathrm{c} 1}$ & & Total flooding quantity & $W_{i}$ & $\mathrm{~N}$ \\
\hline $\begin{array}{l}\text { Original centre of gravity of the } \\
\text { liquid }\end{array}$ & $g_{0}$ & & $\begin{array}{l}\text { Distance between } W_{c 1} L_{c 1} \text { and } \\
W_{1} L_{1}\end{array}$ & $h_{1 i}$ & $\mathrm{~m}$ \\
\hline $\begin{array}{l}\text { New center of gravity of the } \\
\text { liquid }\end{array}$ & $g_{\phi}$ & & $\begin{array}{l}\text { Distance between the breach of } \\
\text { the damaged compartment and } \\
\text { the surface of the damaged } \\
\text { compartment }\end{array}$ & $h_{2 i}$ & $\mathrm{~m}$ \\
\hline $\begin{array}{l}\text { Heeling moment produced by } \\
\text { the inclination of the liquid } \\
\text { surface }\end{array}$ & $M_{l 0}$ & $\mathrm{~m}$ & $\begin{array}{l}\text { Distance between the damaged } \\
\text { compartment's breach and the } \\
\text { sea surface }\end{array}$ & $Z_{i}$ & $\mathrm{~m}$ \\
\hline Mass density (Liquid) & $\rho_{l}$ & $\mathrm{Kg} / \mathrm{m}^{3}$ & $\begin{array}{l}\text { Gravity forces per unit length at } \\
\text { section } x\end{array}$ & $g(x)$ & $\mathrm{N}$ \\
\hline Volume occupied by the liquid & $\nabla_{l}$ & $\mathrm{~m}^{3}$ & Bending moment at section $\mathrm{x}$ & $M(x)$ & N.m \\
\hline $\begin{array}{l}\text { Longitudinal distance between } \\
g_{0} \text { and } g_{\phi}\end{array}$ & $l_{1}$ & $\mathrm{~m}$ & $\begin{array}{l}\text { Center of gravity of damaged } \\
\text { compartment }\end{array}$ & $x_{C G i}, y_{C G i}, z_{C G i}$ & \\
\hline $\begin{array}{l}\text { Transverse distance between } \\
g_{0} \text { and } g_{\phi}\end{array}$ & $l_{2}$ & $\mathrm{~m}$ & $\begin{array}{l}\text { Center of gravity of damaged } \\
\text { ship }\end{array}$ & $X_{C G D}, Y_{C G D}, Z_{C G D}$ & \\
\hline Liquid mass & $m_{l}$ & ton & Torque at section $\mathrm{x}$ & $\mathrm{T}(\mathrm{y}, \mathrm{z})$ & N.m \\
\hline Position vector & $\vec{r}$ & & $\begin{array}{l}\text { Load on the certain ship cross } \\
\text { section of section } x\end{array}$ & $q(\mathrm{y}, \mathrm{z})$ & $\mathrm{N}$ \\
\hline Force $(\mathrm{K})$ vector & $\vec{K}$ & & Three components of force $(\mathrm{K})$ & $K_{X}, K_{Y}, K_{Z}$ & \\
\hline $\begin{array}{l}\text { Three components of the } \\
\text { moment of } \vec{K}\end{array}$ & $M_{X K}, M_{Y K}, M_{Z K}$ & & $\begin{array}{l}\text { Buoyancy center of damaged } \\
\text { ship }\end{array}$ & $X_{C B D}, Y_{C B D}, Z_{C B D}$ & \\
\hline $\begin{array}{l}\text { Coordinates of the force }(\mathrm{K}) \\
\text { functional point }\end{array}$ & $X, Y, Z$ & & $\begin{array}{l}\text { Buoyancy forces per unit length } \\
\text { at section } x\end{array}$ & $b(x)$ & $\mathrm{N}$ \\
\hline $\begin{array}{l}\text { Transverse distance between the } \\
\text { load acting point and the } \\
\text { balance position }\end{array}$ & $l(\mathrm{y}, \mathrm{z})$ & $\mathrm{m}$ & & & \\
\hline
\end{tabular}


However, at present, the calculation used for uprighting process mainly considers the variation of the heeling angle and the draft, neglecting the effects due to the trim of the ship. Consequently, the results of the calculation may be wrong for salvaging ships with complex ship lines, damaged ships and large ships. The force module of a wrecked ship is established considering its buoyancy and stability. The flooding quantity of damaged compartments and the calculation method of the longitudinal strength of the ship are consequently derived. Three different typologies of uprighting processes were simulated by GHS and the variation of reserve buoyancy, stability, shear forces, bending moments and torques during uprighting were obtained.

\section{Typical types of damaged ship}

The uprighting process of a damaged, capsized ship is influenced by buoyancy, stability, and slack tank.

According to the methods for treatment of damaged compartments, the following three conditions can be suggested as typical, in reference to the situation shown in Figure 1.

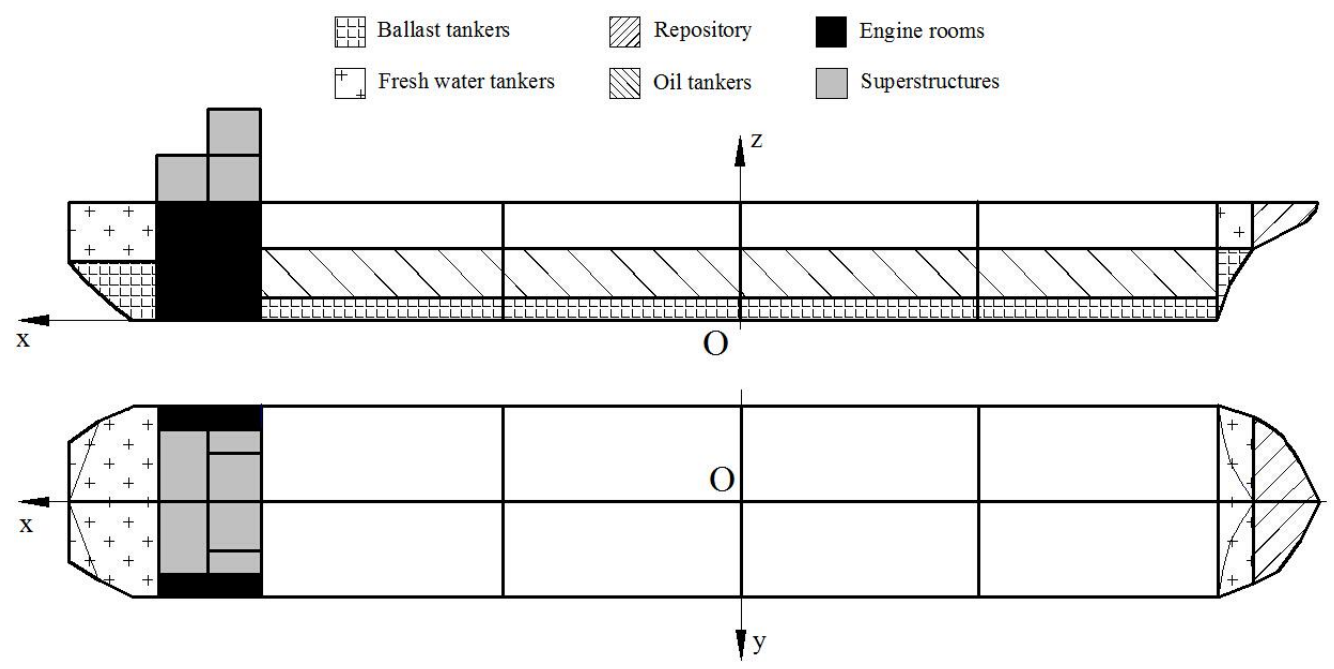

Fig. 1 The diagram of hull and compartments

Case 1: During the uprighting process, damaged compartments underwater cannot be repaired (Figure 2). The damaged compartments regard as intact compartments with 100\% load. Flooding water is considered as part of the dead weight of the vessel. WL is the waterline.

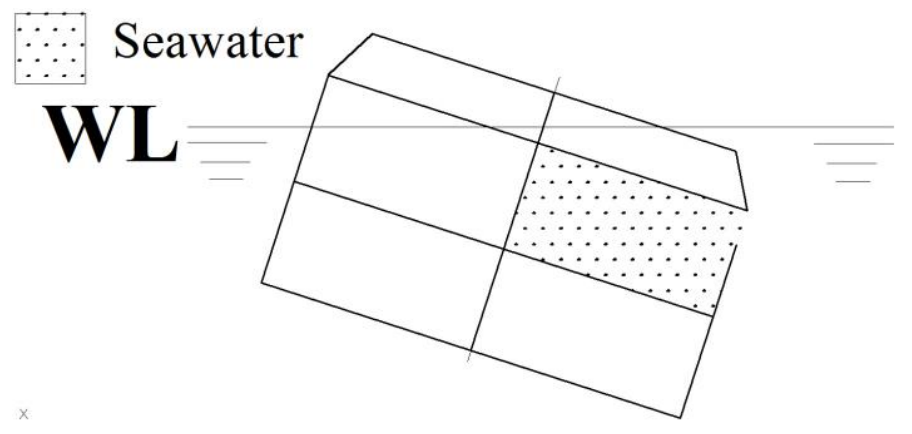

Fig. 2 Diagram of the first case

Case 2: During the uprighting process, the damaged compartments can be repaired, but they cannot be fully drained (Figure 3). Free water in the slack tank adversely affects engineering, however the capsized ship of Case 2 has higher reserve buoyancy than Case 1. A greater uprighting force is required for better uprighting control. 


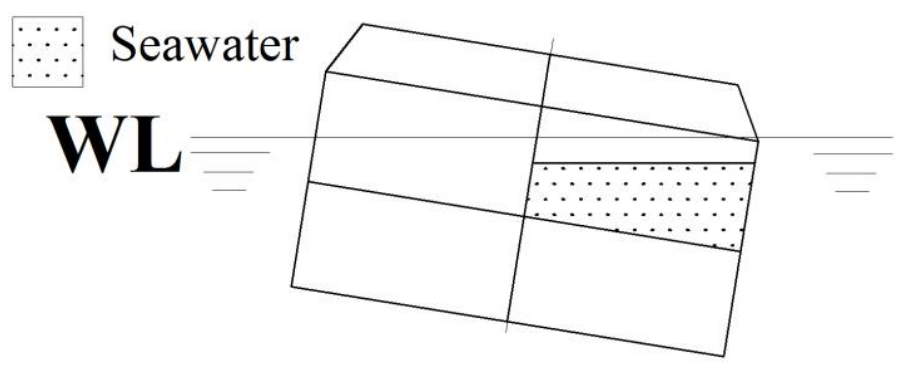

Fig. 3 Diagram of the second case

Case 3: During the uprighting process, the damaged compartments are not repaired. The breach is not sealed, and water continues flowing inside out the compartments (Figure 4). As a result, the total amount of water changes during the course of uprighting. In this case, the insubmersibility of the ship must be considered.

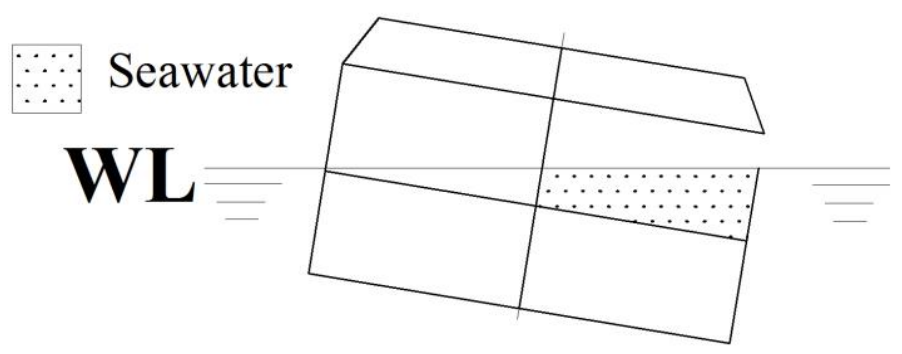

Fig. 4 Diagram of the third case

The success of the uprighting process depends on the accurate calculation of buoyancy, stability, flooding quantity, uprighting moment and longitudinal strength of ship.

\section{Theoretical calculation}

\subsection{Reserve buoyancy}

Calculation of reserve buoyancy contributes to making uprighting plan. The method of sealing compartments or salvage pontoons can be used to increase reserve buoyancy. Reserve buoyancy of damaged ship is composed of four parts:

$$
\Delta_{R B}=\Delta_{0}-\Delta-\rho g \nabla_{f w}-\Delta_{S P}
$$

Where $\Delta_{0}$ is the total buoyancy force of all compartments both above and below the waterplane that are watertight or can be made watertight to withstand the external hydrostatic pressure, $\Delta$ is the displacement of intact ship, $\nabla_{f w}$ is the displacement volume of flooded water, $\Delta_{S P}$ is the buoyancy force of salvage pontoons.

\subsection{Liquid heeling moment}

When a vessel with a partially-filled tank is heeled, the liquid will seek to remain parallel with the waterline. The centre of gravity of the liquid, being the centre of its volume, will move with the liquid and can have a considerable effect upon the vessel's stability.

Figure 5 shows a tank containing a liquid whose surface is free to move within a small angle without touching the tank top or bottom. 


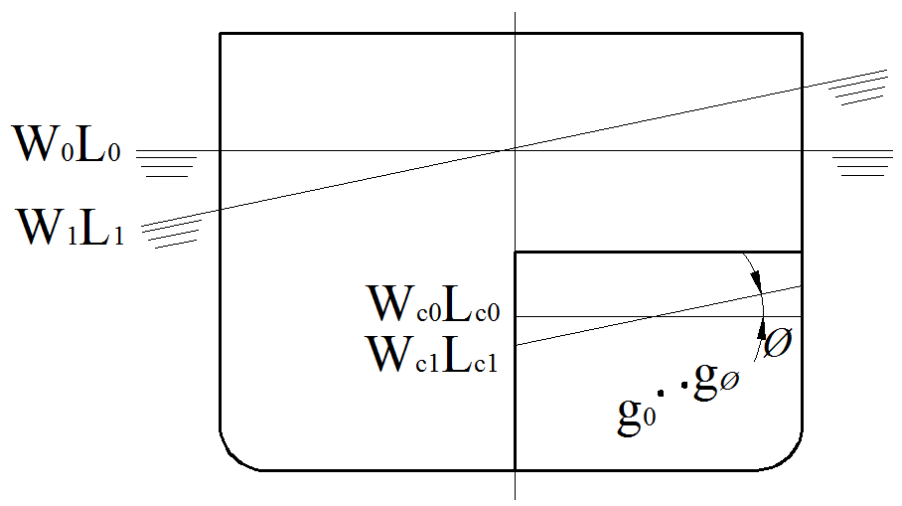

Fig. 5 The ship tilted at a small angle

The heeling moment produced by the inclination of the liquid surface is represented by :

$$
M_{l 0}=\rho_{l} \nabla_{l} g \frac{I_{B}}{\nabla_{l}} \tan \phi=\rho_{l} g I_{B} \tan \phi
$$

Where $\rho_{l}$ is the liquid density, $I_{B}$ is the moment of inertia of the liquid surface with respect to the barycentric axis (of the free surface) parallel to the axis of heeling.

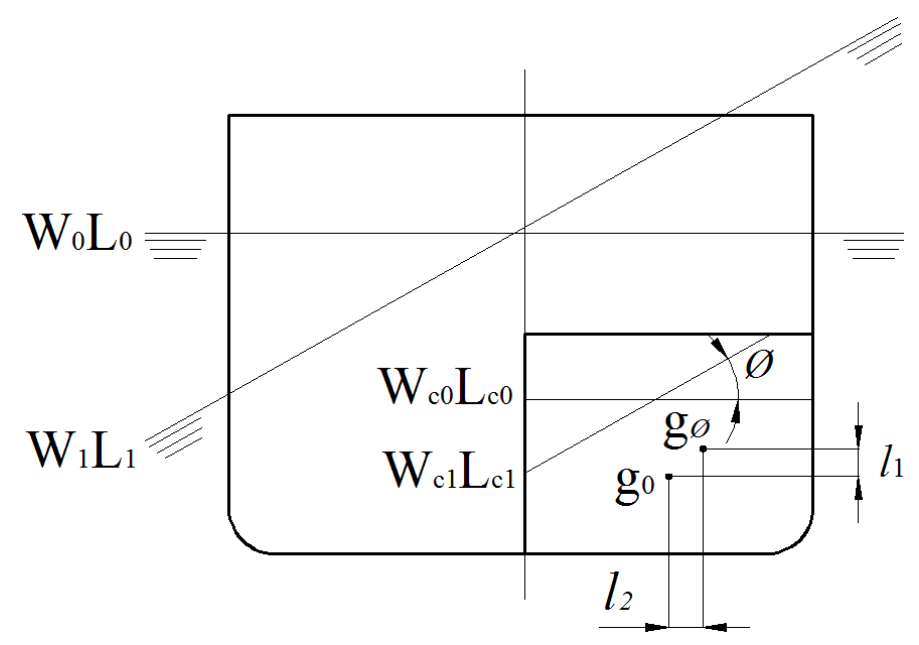

Fig. 6 The ship tilted at a big angle

Often the liquid surface is not free to behave as in Figure 6 and its shape changes when it reaches the tank top or bottom. Then, we cannot use the equations shown above. The same happens when the heeling angle is large and the forms of the tank such that the shape of the free surface changes in a way that cannot be neglected. In such cases the exact trajectory of the centre of gravity must be calculated. As shown in Figure 6, the resulting heeling moment is represented by:

$$
M_{l 1}=m_{l} g\left(l_{1} \sin \phi+l_{2} \cos \phi\right)
$$

Where $m_{l}$ is the liquid mass.

\subsection{Floating parameters}

Generally, the main methods of uprighting include floating pontoon method, hydraulic jack method and floating crane method. These methods are able to rotate the capsized ship by applying external vertical forces through different ways. 
The uprighting process can be divided into numerous static states, with their relative mechanical equilibrium. The position of a floating ship is determined by the relation between a fixed coordinate system and the ship fixed coordinate system.

Figure 7 shows the origin $O_{1}$ of the fixed coordinate system $O_{1} \xi \eta \zeta$, which exists in the cross area of water plane area of ship under the upright floating condition, the midship section, and the longitudinal mid-section. The origin $O$ of the ship fixed coordinate system Oxyz exists in the cross area of the base plane, the midship section, and the longitudinal midsection. The axes' directions are as follows: $O x$ is the intersection of the base plane and the longitudinal mid-section; the stern represents the positive direction. $O y$ is the intersection of the base plane and the midship section; the starboard represents the positive direction. $O z$ is the intersection of the longitudinal mid-section and the midship section; the positive direction is over the base plane.

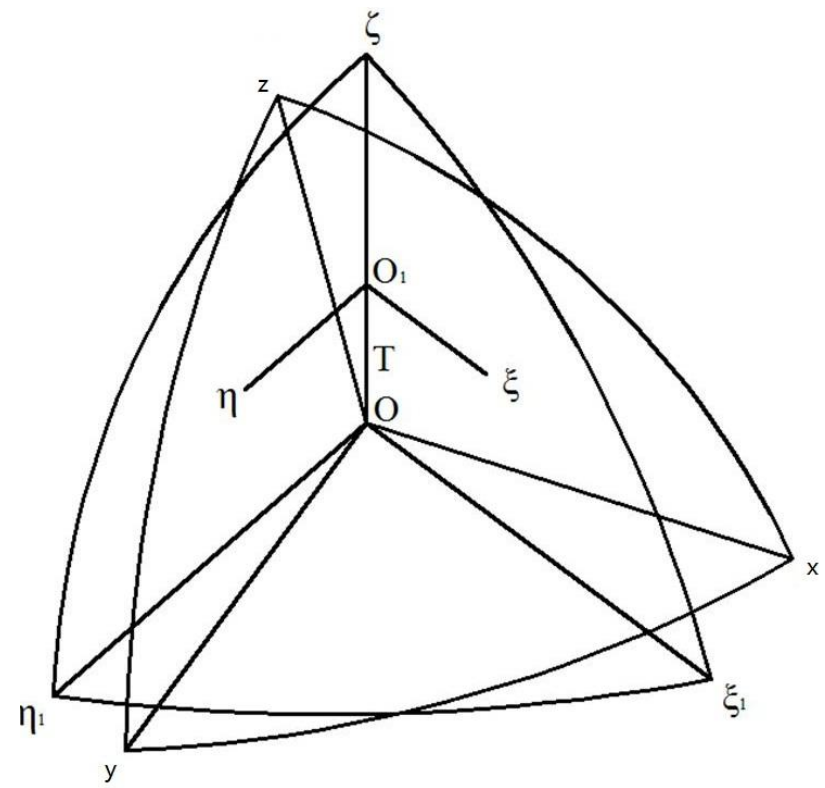

Fig. 7 The fixed coordinate system and the ship fixed coordinate system

Generally, Euler angle parameters, Vlasov angle parameters and Bolegman angle parameters can be used to determine floatation. Vlasov angle parameters are widely used in China, especially for damaged ships, but the parameters lead to values of draft approaching to infinity for heeling angle or trim up to $90^{\circ}$. Applying Bolegman angle parameters, the value of draft approach infinity for trim is $90^{\circ}$. Therefore, in uprighting calculation, Vlasov angle parameters and Bolegman angle parameters may bring obvious error. To study the uprighting process of capsized ship sufficiently, theoretical calculation are made applying Euler angle parameters.

For the convenience of engineering analysis, heading is $0^{\circ}$ to avoid any angular displacements. In addition, the origin of the fixed coordinate system is coincident to the origin of the ship fixed coordinate system, and the relation between the two systems is described by the following equation:

$$
\left[\begin{array}{l}
\xi \\
\eta \\
\zeta
\end{array}\right]=\left[\begin{array}{ccc}
\cos \phi & \sin \phi \sin \theta & -\cos \phi \sin \theta \\
0 & \cos \phi & \sin \phi \\
\sin \theta & -\sin \phi \cos \theta & \cos \phi \cos \theta
\end{array}\right]\left[\begin{array}{l}
x \\
y \\
z
\end{array}\right]
$$




\subsection{Ship stability}

Due to the influence of underwater ship lines, freeboard and superstructure, the computation of initial stability is not applicable for a big-angle tilted ship [21]. The righting arm of damaged ship at any spatial position is represented by:

$$
\overline{G Z}=\left\{\begin{array}{l}
\sqrt{\left(\xi_{B}-\xi_{G}\right)^{2}+\left(\eta_{B}-\eta_{G}\right)^{2}} \\
-\sqrt{\left(\xi_{B}-\xi_{G}\right)^{2}+\left(\eta_{B}-\eta_{G}\right)^{2}}
\end{array} ;\left\{\begin{array}{l}
\cos (\overrightarrow{G B}, \vec{j})<0 \\
\cos (\overrightarrow{G B}, \vec{j})>0
\end{array}\right.\right.
$$

Where

$$
\begin{aligned}
& \sqrt{\left(\xi_{B}-\xi_{G}\right)^{2}+\left(\eta_{B}-\eta_{G}\right)^{2}}=\left\{\left[\left(x_{B}-x_{G}\right) \cos \theta-\left(z_{B}-z_{G}\right) \cos \phi \sin \theta\right]^{2}+\right. \\
& {\left[\left(y_{B}-y_{G}\right) \cos \phi+\left(z_{B}-z_{G}\right) \sin \phi\right]^{2}+\left[\left(y_{B}-y_{G}\right) \sin \phi \sin \theta+\left(z_{B}-z_{G}\right) \cos \phi \sin \theta\right]^{2}+} \\
& {\left[\left(x_{B}-x_{G}\right) \cos \theta+\left(y_{B}-y_{G}\right) \sin \phi \sin \theta\right]^{2}-} \\
& \left.\left(x_{B}-x_{G}\right)^{2} \cos ^{2} \theta-\left(y_{B}-y_{G}\right)^{2} \sin ^{2} \phi \sin ^{2} \theta-\left(z_{B}-z_{G}\right)^{2} \cos ^{2} \phi \sin ^{2} \theta\right\}^{\frac{1}{2}}
\end{aligned}
$$

The essence of the uprighting process is the rotation process, which starts when the righting force moment is greater than the righting moment. The righting moment is represented by:

$$
M_{S}=\left(\Delta+\rho g \nabla_{f w}\right) \overline{G Z}
$$

\subsection{The mathematical model}

In the Cartesian coordinates, the moment of the force vector $\vec{K}$ acting on the origin is defined as the cross product of the position vector and $\vec{K}$.

$$
\vec{M}=\vec{r} \times \vec{K}=\left[\begin{array}{ccc}
\vec{i} & \vec{j} & \vec{k} \\
X & Y & Z \\
K_{X} & K_{Y} & K_{Z}
\end{array}\right]=\begin{aligned}
& \left(Y K_{Z}-Z K_{Y}\right) \vec{i}+\left(Z K_{X}-X K_{Z}\right) \vec{j}+ \\
& \left(X K_{Y}-Y K_{X}\right) \vec{k}
\end{aligned}
$$

The moment of $\vec{K}$ is resolved into three components along the coordinate axis:

$$
\left\{\begin{array}{l}
M_{X K}=Y K_{Z}-Z K_{Y} \\
M_{Y K}=Z K_{X}-X K_{Z} \\
M_{Z K}=X K_{Y}-Y K_{X}
\end{array}\right.
$$

Where $X, Y, Z$ are the coordinates of the force functional point.

According to equation (7) and (8), the ship's weight is resolved into three components along the coordinate axes where $W$ is the gravity of the ship:

$$
\left\{\begin{array}{l}
W_{X}=-W \sin \theta \\
W_{Y}=W \sin \phi \cos \theta \\
W_{Z}=-W \cos \phi \cos \theta
\end{array}\right.
$$


The moment of ship's weight is resolved into three components along the coordinate axes:

$$
\left\{\begin{array}{l}
M_{X G}=-Y_{G} W \cos \phi \cos \theta-Z_{G} W \sin \phi \cos \theta \\
M_{Y G}=-Z_{G} W \sin \theta+X_{G} W \cos \phi \cos \theta \\
M_{Z G}=X_{G} W \sin \phi \cos \theta+Y_{G} W \sin \theta
\end{array}\right.
$$

In the same way, the ship's buoyancy force moment is resolved into three components along the coordinate axes:

$$
\left\{\begin{array}{l}
M_{X B}=Y_{B} \Delta \cos \phi \cos \theta+Z_{B} \Delta \sin \phi \cos \theta \\
M_{Y B}=Z_{B} \Delta \sin \theta-X_{B} \Delta \cos \phi \cos \theta \\
M_{Z B}=-X_{B} \Delta \sin \phi \cos \theta-Y_{B} \Delta \sin \theta
\end{array}\right.
$$

Where $\Delta$ is the buoyancy force of the ship.

In the same way, righting force moment is resolved into three components along the coordinate axes:

$$
\left\{\begin{array}{l}
M_{X F}=Y_{F} F \cos \phi \cos \theta+Z_{F} F \sin \phi \cos \theta \\
M_{Y F}=Z_{F} F \sin \theta-X_{F} F \cos \phi \cos \theta \\
M_{Z F}=-X_{F} F \sin \phi \cos \theta-Y_{F} F \sin \theta
\end{array}\right.
$$

Where $X_{F}, Y_{F}, Z_{F}$ are the coordinates of the righting force functional point.

According to equation (10), (11) and (12), equation (13) is obtained:

$$
\left\{\begin{aligned}
M_{X} & =M_{X G}+M_{X B}+M_{X F} \\
& =\left(-Y_{G} G+Y_{B} \Delta+Y_{F} F\right) \cos \phi \cos \theta+\left(-Z_{G} G+Z_{B} \Delta+Z_{F} F\right) \sin \phi \cos \theta \\
M_{Y} & =M_{Y G}+M_{Y B}+M_{Y F} \\
& =\left(-Z_{G} G+Z_{B} \Delta+Z_{F} F\right) \sin \theta+\left(X_{G} G-X_{B} \Delta-X_{F} F\right) \cos \phi \cos \theta \\
M_{Z} & =M_{Z G}+M_{Z B}+M_{Z F} \\
& =\left(X_{G} G-X_{B} \Delta-X_{F} F\right) \sin \phi \cos \theta-\left(-Y_{G} G+Y_{B} \Delta+Y_{F} F\right) \sin \theta
\end{aligned}\right.
$$

The relationship between $M_{X}, M_{Y}$ and $M_{Z}$ is represented by:

$$
M_{X} \sin \theta-M_{Y} \sin \phi \cos \theta+M_{Z} \cos \phi \cos \theta=0
$$

The static equilibrium equation of gravity, buoyancy force and righting force can be obtained.

$$
\Delta+F-W=0
$$

Then, the mechanical model of uprighting is established. 


$$
\left\{\begin{aligned}
\Delta+ & F-W=0 \\
M_{Y} & =M_{Y G}+M_{Y D}+M_{Y F} \\
& =\left(-Z_{G} W+Z_{B} \Delta+Z_{F} F\right) \sin \theta+\left(X_{G} W-X_{B} \Delta-X_{F} F\right) \cos \phi \cos \theta \\
M_{Z} & =M_{Z G}+M_{Z B}+M_{Z F} \\
& =\left(X_{G} W-X_{B} \Delta-X_{F} F\right) \sin \phi \cos \theta-\left(-Y_{G} W+Y_{B} \Delta+Y_{F} F\right) \sin \theta
\end{aligned}\right.
$$

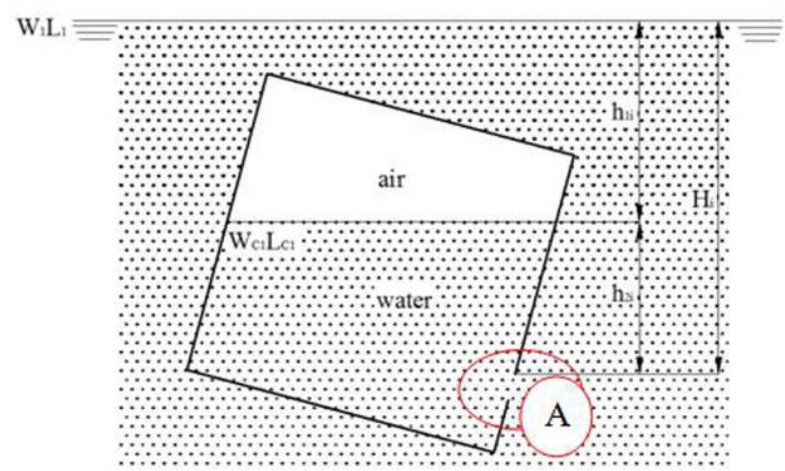

Fig. 8 The diagram of damaged compartment

Figure 8 shows a flooded damaged compartment, which is not filled with water because of air. Bernoulli equation can be used to obtain the inflow quantity of the damaged compartment of the i-th value [22]:

$$
q_{i}=\left\{\begin{array} { l } 
{ \mu A \sqrt { 2 g ( Z _ { i } - h _ { 2 i } ) } } \\
{ - \mu A \sqrt { 2 g ( Z _ { i } - h _ { 2 i } ) } }
\end{array} \quad \left\{\begin{array}{l}
Z_{i-1}<Z_{i} \\
Z_{i-1}>Z_{i}
\end{array} \quad i=1,2,3, \ldots, n\right.\right.
$$

Here, $A$ is the area of the damage opening; $\mu$ is the flow coefficient.

The total water quantity of damaged compartment of the i-th value can be obtained:

$$
\nabla_{i}=\nabla_{I}+\sum_{i=1}^{i} q_{i}
$$

Where $\nabla_{I}$ is the initial flooding quantity.

Thus, the total flooding quantity can be solved during uprighting:

$$
W_{i}=\rho g \nabla_{i}
$$

The center of gravity of a damaged compartment $\left(x_{C G i}, y_{C G i}, z_{C G i}\right)$ can be obtained based on ship lines, inclination angle and the total flooding quantity. Then, the center of gravity of damaged compartments $\left(x_{C G}, y_{C G}, z_{C G}\right)$ is solved.

The center of gravity of the damaged ship is determined according to the intact ship and the total flooding quantity [23]. 


$$
\left\{\begin{array}{l}
X_{C G D}=\frac{X_{C G} W+x_{C G} \rho \nabla_{f w} g}{W+\rho \nabla_{f w} g} \\
Y_{C G D}=\frac{Y_{C G} W+y_{C G} \rho \nabla_{f w} g}{W+\rho \nabla_{f w} g} \\
Z_{C G D}=\frac{Z_{C G} W+z_{C G} \rho \nabla_{f w} g}{W+\rho \nabla_{f w} g}
\end{array}\right.
$$

The buoyancy center of damaged ship can be obtained based on buoyancy center of intact ship and the center of gravity of damaged ship [24].

$$
\left\{\begin{array}{l}
X_{C B D}=\frac{\Delta X_{C B}-\rho g \nabla_{f w} x_{C G}}{\Delta-\rho g \nabla_{f w}} \\
Y_{C B D}=-\frac{\rho g \nabla_{f w} y_{C G}}{\Delta-\rho g \nabla_{f w}} \\
Z_{C B D}=\frac{\Delta Z_{C B}-\rho g \nabla_{f w} z_{C G}}{\Delta-\rho g \nabla_{f w}}
\end{array}\right.
$$

Where $v_{2}$ is the volume of watertight compartments below initial water line.

During uprighting, the ship is considered to be in equilibrium under the action of weight, buoyancy forces and righting force. The sum of buoyancy forces and righting force acting on a ship must be equal to the weight of the ship itself. However, the distribution of those forces along the ship length is not uniform. The difference between those values on a certain cross section of the ship gives the longitudinal load as follows:

$$
q(x)=g(x)-b(x)-f(x)
$$

Where $g(x)$ expresses the gravity forces per unit length at section $\mathrm{x}, b(x)$ expresses the buoyancy forces per unit length at section $\mathrm{x}$, and $f(x)$ is the righting force per unit length at section $\mathrm{x}$.

Then the shear force and the bending moment at section $\mathrm{x}$ can be expressed as follows:

$$
\begin{aligned}
& N(x)=\int_{0}^{x} q(x) d x \\
& M(x)=\int_{0}^{x} \int_{0}^{x} q(x) d x d x
\end{aligned}
$$

In addition, the torque at section $\mathrm{x}$ is as follows:

$$
\mathrm{T}(\mathrm{y}, \mathrm{z})=\int_{0}^{y} \int_{0}^{z} q(\mathrm{y}, \mathrm{z}) l(\mathrm{y}, \mathrm{z}) \mathrm{d} y \mathrm{~d} z
$$

Where $q(\mathrm{y}, \mathrm{z})$ is the load on the certain ship cross section of section $\mathrm{x}, l(\mathrm{y}, \mathrm{z})$ is the distance between the load acting point and balance position.

Uprighting calculation is a multifarious course. Correlative software can improve design efficiency and shorten design time. This paper adopts the GHS software to simulate the uprighting process. 


\section{Simulation description}

Manual calculation, the table method, experiential formulas, and semi-empirical formulas are used to calculate the righting force in traditional salvage engineering. Which have limited significance in salvage engineering because the process is slow and imprecise. Traditional calculation cannot determine the exact necessary uprighting force, so equipments must be continually altered on site. GHS software can overcome the problems of traditional calculations.

The GHS tools fall into two groups involved in performing a hydrostatic analysis. One is the tool for building a model of a vessel, the other is the tool for analyzing the model. In phase one, the buoyant part of the hull must be defined in a manner suitable to the degree of precision required. Internal subdivisions and tankage arrangements may be specified as well as non-buoyant superstructure for calculations. Phase two produces hydrostatic/stability evaluation data based on the model built in phase one. This data may include tables and curves of hydrostatic properties, stability and tank characteristics; or a simulation-oriented approach may be taken, subjecting the model to conditions of loading and damage while observing the response.

Ship model quality affects simulation accuracy. Some principles should be obeyed during the modeling process: twisted hull lines must be avoided to decrease computing errors; the changing active model area must be encrypted to improve solution precision; the line segment quantity in areas with little changes in model intensity should be controlled to expediate calculation. There are two methods for GHS software modeling: interface operation and an editor program. This paper explores the editor program method.

The hull model must be established based on ship lines plans. When creating a vessel model, the buoyant part of the hull must be defined in a manner suitable to the degree of necessary precision. The hull is divided into different sections (The hull of a common ship can be represented by 21 frames, but ships with more complex surfaces require more frames); the longitudinal coordinate of every section should be determined. The section consists of many points, which can be obtained by the transverse and vertical coordinates of points. Then, compartment models are built based on the compartment diagram. Here, compartment permeability and cargo loads can also be set.

Using the ship in Figure 9 as an example, origin $O$ crosses the area of the base plane, the midship section, and the longitudinal mid-section, which is $3 \mathrm{~m}$ from the stern. The axis direction is as follows: $O x$ is the intersection of the base plane and the longitudinal midsection; the stern represents the positive direction. $O y$ is the intersection of the base plane and the midship section; the starboard represents the positive direction. $O z$ is the intersection of the longitudinal mid-section and the midship section; the positive direction is over the base plane. Table 1 shows the ship's principal dimensions.

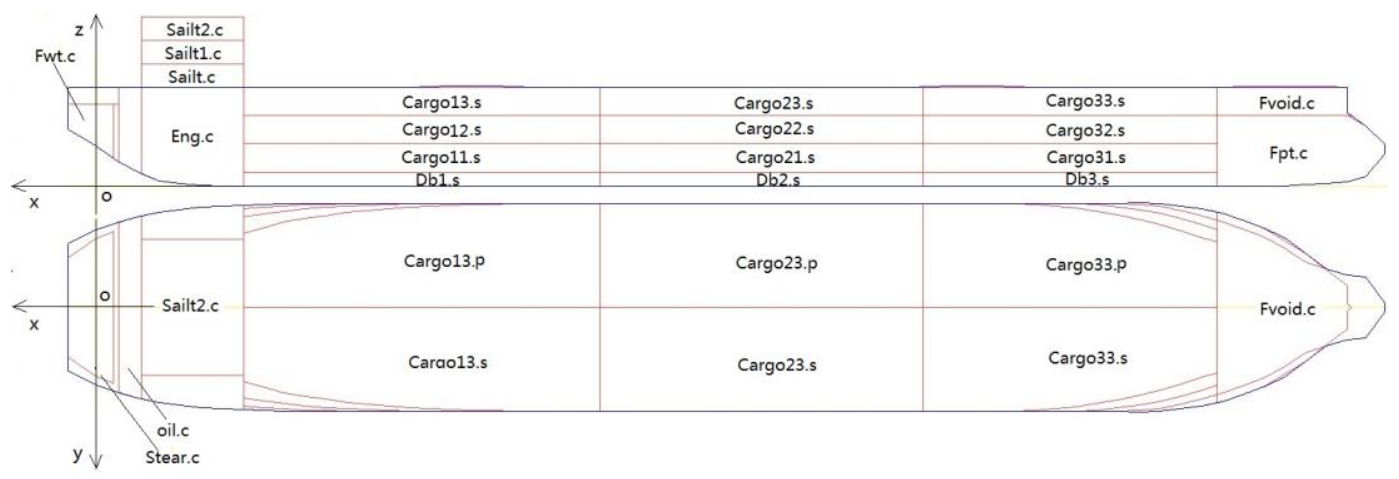

Fig. 9 Hull and cabins 
Table 2 The principal dimensions of the intact ship

\begin{tabular}{|cccc|}
\hline Length Overall & Breadth & Molded depth & Weight \\
$(\mathrm{m})$ & $(\mathrm{m})$ & $(\mathrm{m})$ & $($ ton$)$ \\
139 & 22 & 10.556 & 3744.25 \\
\hline
\end{tabular}

\section{Simulation scheme}

According to related literature and actual real salvages, some ships will still float on water although some compartments are damaged. The ship's profile line, cargo, and superstructure affect the uprighting process. Water flow, tide, and wind are also important factors to consider [25-27]. In traditional calculations for righting capsized wrecks, calculation results are often inaccurate because the equation only analyzes certain stages of the uprighting process [28-30].

The example used for this study regards a ship with a big gash caused by a collision. The ship listed $169.15^{\circ}$ to starboard, it had a trim of $-0.41^{\circ}$, and an origin draft of $-8.273 \mathrm{~m}$. Three uprighting schemes of uprighting were evaluated.

Scheme A: The compartments opposite to the damaged ones were unloaded. The damaged bulkhead was entirely cleared and rewelded. The damaged compartments were drained. Then, the ship listed $180^{\circ}$ to starboard.

Scheme B: The breaches in the damaged compartments were sealed. About $15 \%$ of the compartments volume was filled with water, due to drainage technique limitation.

Scheme C: The ship was righted directly. The breaches were not sealed and therefore water continued flowing inside out the compartments. As a result, the total amount of water changed during the course of uprighting.

During the uprighting process, the superstructure is not sealed and the same righting method was applied for comparing the three schemes.

\subsection{Reserve buoyancy}

To ensure adequate reserve buoyancy it is necessary to verify the counter-flooding calculation. The reserve buoyancy of damaged ship is $224471.9 \mathrm{kN}$. The maximum displacement of the damaged ship is $115609.2 \mathrm{kN}$. Thus, the ship could be righted directly.

\subsection{Analysis on stability of capsized ships}

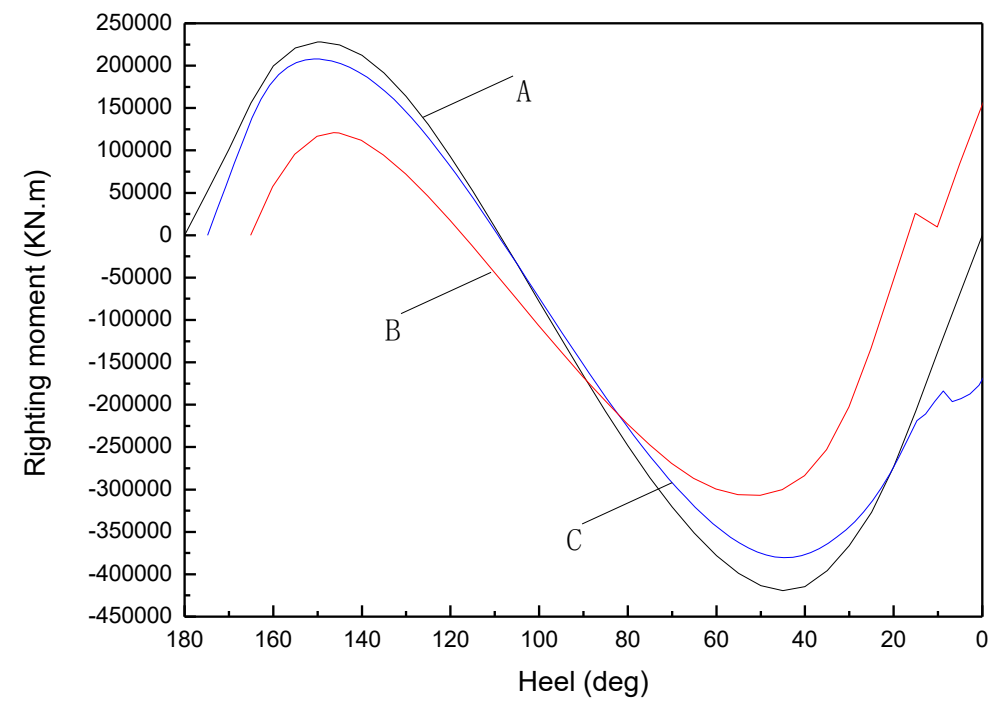

Fig. 10 The static stability curves of capsized ships 
Static stability of the capsized ship determines the difficulty of uprighting (Figure 10). During uprighting, the ship begins to rotate when the righting force moment is greater than the righting moment. Negative values of the curves represent the stability of the ship in upright condition. Negative stability is helpful during the uprighting process, because the ship is prone to return to the neutral position without righting force. Then a moment in the opposite direction is needed to maintain a steady speed, which prevents the ship from being damaged again or from capsizing again.

The proportion between the maximum righting moment and the maximum righting moment in the opposite direction was $0.544,0.546$ and 0.395 for schemes A, B and C, respectively. In later phases of the process, the righting force moment in the opposite direction and the righting force moment in the positive direction were needed for schemes $\mathrm{B}$ and $\mathrm{C}$, respectively.

If the longitudinal load of the hull exceeds its limit stress value, there is a serious risk for serious accident and injury. Thus, from the strength analysis of the hull depends the success or failure of the salvage project. The variation of the longitudinal strength were evaluated in nine positions along the hull, and $-4.8,-13.26,-15.6,-30.94,-53.4,-61.88$ , $-87.6,-103.87$, and -118.8 were the longitudinal coordinates of the nine selected sections (Figure 11).

\subsection{The longitudinal shear forces during uprighting}

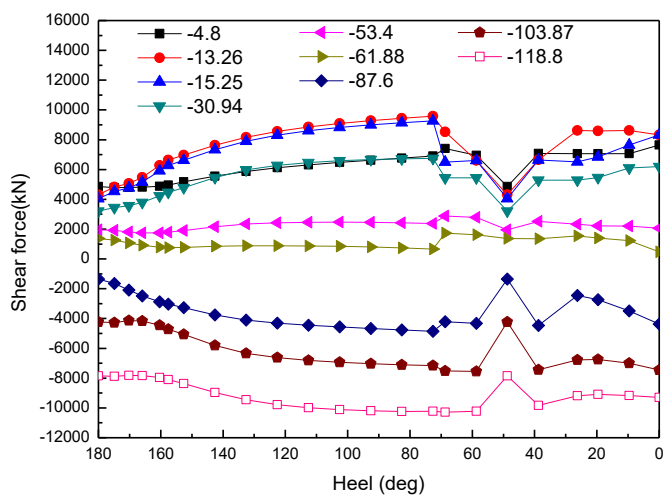

Fig. 11 Variation of the longitudinal shear force of A

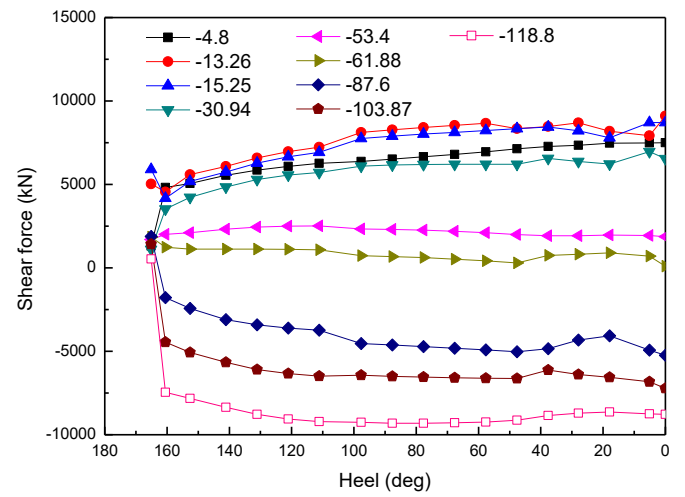

Fig. 12 Variation of the longitudinal shear force of B

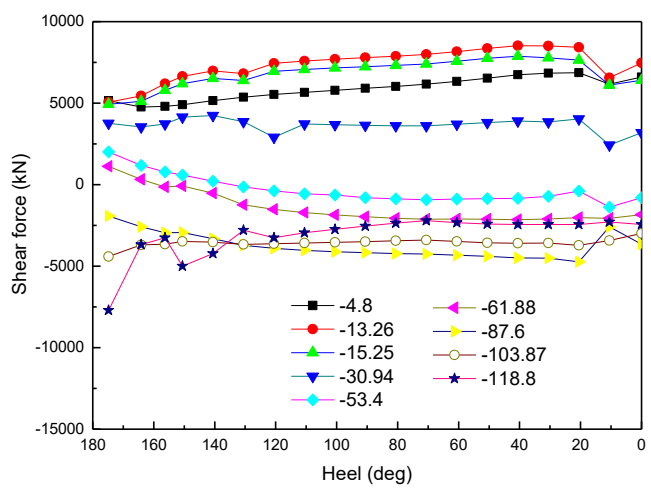

Fig. 13 Variation of the longitudinal shear force of C

The variation of the longitudinal shear forces during uprighting process showed that the shear forces in the mid-ship were relatively small, while heavy carrying capability and small displacement near the front of ship produced greater shear forces. The shear forces at stern were relatively big, due to the superstructure and small displacement. In scheme B, a large variation of shear forces in the front half part of the ship at the beginning of the project. In 
scheme $\mathrm{C}$, the damaged compartments of the bow had a greater water flow than other compartments, which contributed to a large variation of shear forces, and shear forces of midship decreased during uprighting.

\subsection{The bending moments during uprighting}

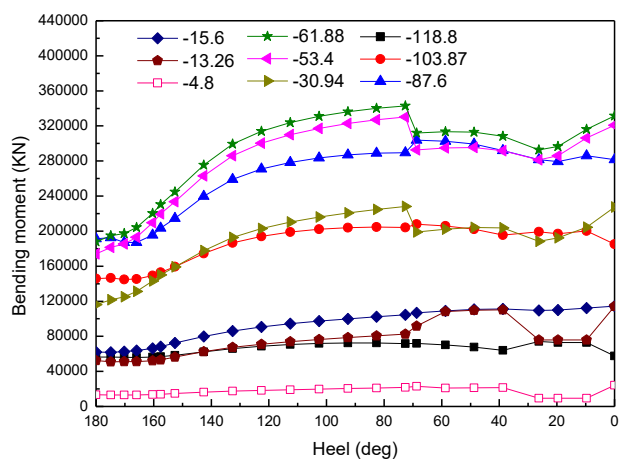

Fig. 14 Variation of the bending moments of A

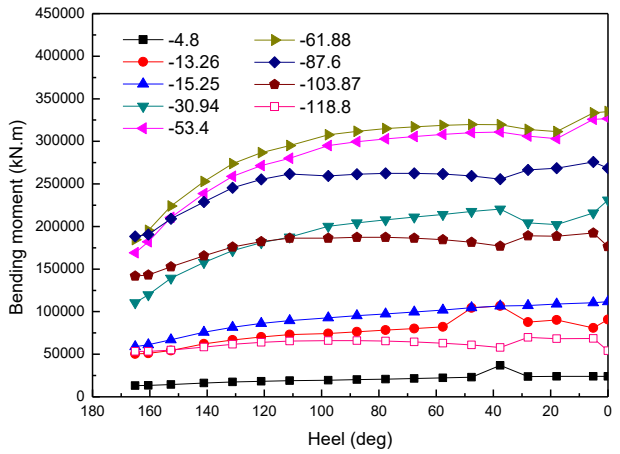

Fig. 15 Variation of the bending moments of B

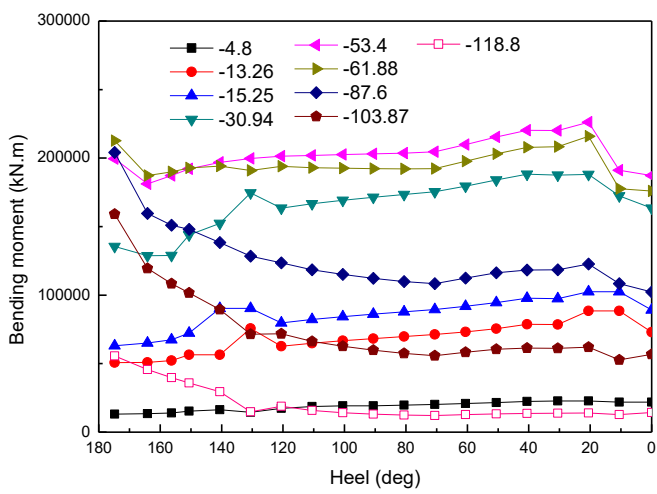

Fig. 16 Variation of the bending moments of $\mathrm{C}$

Still water bending moment is the most important operation for strength calculation. Figure 12 shows that the trends of bending moment in different longitudinal position of hull were approximately the same for schemes A and B. In scheme C, early in the uprighting, $94.7 \%$ of seawater in the peak tank was gone, while the quantity of water inflow was very small. During uprighting, the trim change of the ship was $1.48^{\circ}$; the bending moment of the hull with the longitudinal coordinates $-118.8,-103.87$ and -87.6 reduced by $288.4 \%$, $201.5 \%$, and $99.5 \%$, respectively. The trends of bending moment of the stern of scheme $\mathrm{C}$ were consistent with scheme A and scheme B.

5.5 The torques during uprighting

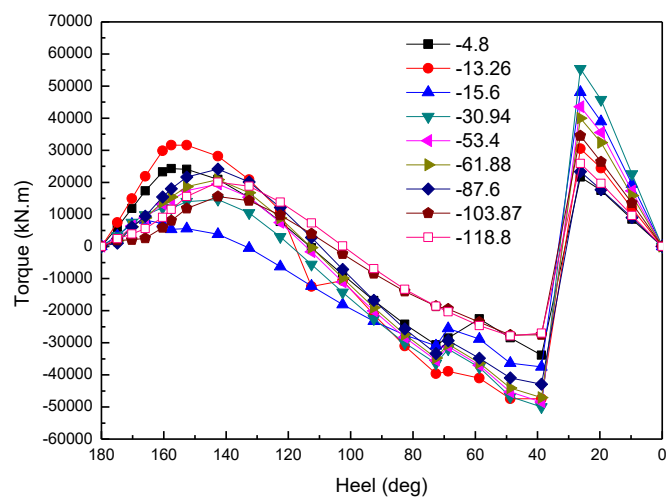

Fig. 17 Variation of the torques of A

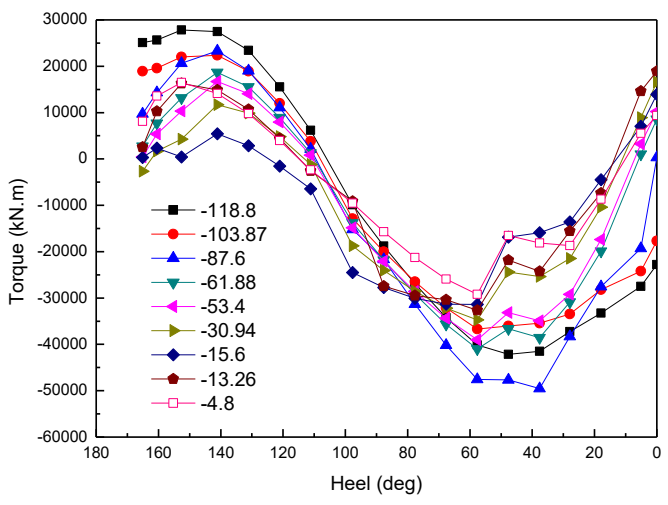

Fig. 18 Variation of the torques of B 


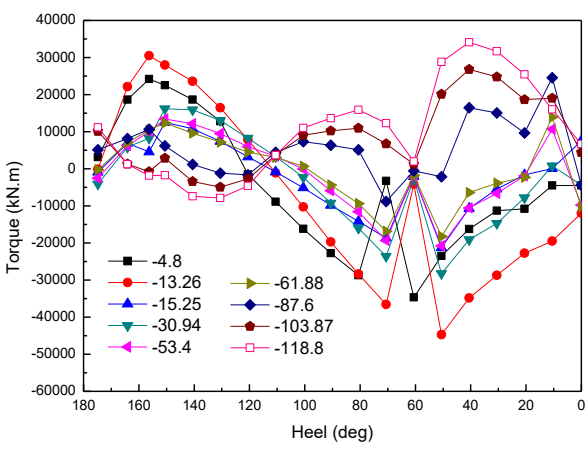

Fig. 19 Variation of the torques of $\mathrm{C}$

The uprighting process is a rotation process. The uneven distribution of the transverse forces may cause the structure torsion along the hull. The changing curves of torques in the three schemes are presented in Figure 13. Scheme A has the maximum torques, while torques in scheme B follow the same trend of A, but with relatively small values. In addition, the variation curves of torques for $\mathrm{A}$ and $\mathrm{B}$ are similar to the static stability curves. The torques of $\mathrm{B}$ and $\mathrm{C}$ under the initial state and the neutral position are unequal to zero, due to negative initial stability. In scheme $\mathrm{C}$, torques is greatly influenced by flooding water, and the trends of torques on the bow, mid-ship and stern are the same respectively, while the maximum negative torque is produced on the stern of the ship.

\section{Conclusions}

In this paper, mathematical models of righting force, flooding quantity and longitudinal strength were established based on the hydrostatics theory for ships. The tree-dimensional ship model was built via GHS to simulate the righting of capsized ships. The main results are as follows:

(1) The stability of the inverted ship can be reduced by unloading stowage at a higher level of ship, which is beneficial to the uprighting process. Three different schemes of uprighting processes were simulated by GHS: scheme A, with no water in the damaged compartment and for which the damaged bulkhead was entirely cleared and rewelded; scheme $\mathrm{B}$, with $15 \%$ of the volume of the compartment filled with water due to drainage technique limitation; and scheme $\mathrm{C}$, with some water in the damaged compartment and breaches were not sealed. For scheme A, work time increased due to the need of complete repair of damaged compartments, and the larger righting force moment was produced. For scheme B, the time for sealing damaged compartments was reduced, but the free water in the damaged compartments decreased the stability of inverted ship, which in turns reduced the difficulty of uprighting, especially in comparison to A. Scheme C considerably reduced the time of preparatory work, and decreased the stability of inverted ship in some degree, but it also increased the difficulty of uprighting due to flooding water. Thus, scheme B was confirmed as the most reasonable.

(2) During uprighting, controlling the variation of trim is beneficial. The longitudinal distribution of weight, displacement and righting force should also be considered. Adjusting ballast water reduces pitching motion, but it can also produce big shear forces. Superstructure also causes a local increase of shear force.

(3) The uprighting process is a rotation process. The distribution of torques along hull should also be calculated, especially for damaged ship with large openings. For ships with negative stability, the torques still need be considered when the ship is pulled upright completely. The torques vary complicatedly due to the water flowing inside out the damaged compartments, so calculation of the torques must be made to ensure the safety of hull. 


\section{Acknowledgments}

The authors thanks the anonymous reviewers for their valuable remarks and comments.

This paper is funded by the Fundamental Research Funds for the Central Universities (3132016354, 3132016069), the Key Technology and Demonstration of Helicoper Rescue Ability Promotion of Severe Sea Condition(2013328225080), and National Sci-Tech Support Plan (2014BAK05B06).

\section{REFERENCES}

[1] Lin, J. X., R. Y. Wang, Z. C. Sun, 2006, “The salvage of the ship Yinheshanl68,” Proceedings of China International Rescue \& Salvage Conference 2006(CIRSC), Kunming, China, pp. 83-89. （in Chinese )

[2] Zhao, X. F., 1988, “The calculation of subdivision and damage stability of ship,” J. Journal of dalian university of technology, 28(1), pp. 87-92. (in Chinese)

[3] Lin, Y., T. L. Li, Z. S. Ji, 2001, "Ship damage floating calculation,” J. Journal of dalian university of technology. 14(1), pp. 85-89. (in Chinese)

[4] Li, Y. M., 2002, "Study on the Buoyancy、Stability、 Longitudinal Strength of Lumber Carrier and Simulation of Damaged Flooding," MA.Sc. thesis, Dalian Maritime University, Dalian, China. （in Chinese )

[5] Couser, P. R., 2004, “ON THE EFFECT OF TANK FREE SURFACES ON VESSEL STATIC STABILITY," J. International Journal of Maritime Engineering.

[6] Guo D. H., He, G. J. and Chen, Y. S., 1996, "Determination of the Free Surface in a Liquid Tank," J. Communications in Nodimm Science \& Numakal Simukion, 1(3), pp. 56-58. http://dx.doi.org/10.1016/s1007-5704(96)90013-1.

[7] Ruponen, P., 2007, “PROGRESSIVE FLOODING OF A DAMAGED PASSENGER SHIP," Ph.D. thesis, Helsinki University of Technology, Helsinki, Finland.

[8] Vermeer, H., Vredeveldt, A.W. and Journée, J.M.J, 1994, "Mathematical Modelling of Motions and Damaged Stability of Ro-Ro Ships in the Intermediate Stages of Flooding," Fifth International Conference on Stability of Ships and Ocean Structures, Florida, USA, pp. 1-9.

[9] Mironiuk, W., 2010, “The Influence of the Flooding Damaged Compartment on the Metacentric Height Ship Type 888," J. International Journal on Marine Navigation and Safety of Sea Transportation, 4(4), pp. 473-474.

[10] Yao, T., 2003, “Hull girder strength,” J. Marine Structures, 16, pp. 1-13. http://dx.doi.org/10.1016/S0951-8339(02)00052-7.

[11] Ivanov, L. D., 2007, “On the relationship between maximum still water shear forces, bending moments, and radii of gyration of the total ship's weight and buoyancy forces," J. Ships and Offshore Structures, 2(1), pp. 39-47. http://dx.doi.org/10.1533/saos.2006.0147.

[12] ŽAJA, D., ZAMARIN, A., and HADJINA, M., 2007, "LONGITUDINAL STRENGTH OF A CONTAINER SHIP,” J. Eng. Rev., 27(1), pp. 55-66.

[13] Khan, I. A., and Das., P. K., 2008, "Reliability analysis of intact and damaged ships considering combined vertical and horizontal bending moments," J. Ships and Offshore Structures, 3(4), pp. 371-384. http://dx.doi.org/10.1080/17445300802369950.

[14] Paik, J. K., Thayamballi, A. K., Pedersen, P. T. and Park, Y. I., 2001, "Ultimate strength of ship hulls under torsion," J. Ocean Engineering, (28), pp. 1097-1133.

[15] Ge. W., Chen, Y.J., Zhang, H.Q., and Peng, H., 2002, "Longitudinal strength of ships with accidental damages," J. Marine Structures, (15), pp. 119-138.

[16] Wang, D. N., and Bi, Y. T., 2010, “A Brief Introduction on GHS Software in Wreck Removal Operation," In: Proceedings of the 6nd China international rescue and salvage conference, Xian, China, pp. 169-171. (in Chinese)

[17] Liu, Y. H., Huang, X. L., Huang, X. B., 2006, "Research on aided design software about salvage of sunken ship,” J. China Water Transport(Academic Version), 6(1), pp. 131-133. （in Chinese ) 
[18] Liu, H. M, and Gu, Z. Y., 2004, "The design and realization of the auxiliary design software of layout for salvage boat," In: The 2004 Salvage annual Symposium, Haerbin, China, pp, 65-70. (in Chinese)

[19] Liu, H. M., Gu, Z. Y., Lu Z., Li, X. H., Duan, Y., and Hu, P., 2006, "PDA Application and Empolder in the Field of Rescue Salvage and Diving," In: The 2006 Salvage annual Symposium, Kunming, China, pp. 93-95. (in Chinese)

[20] Huang, X. K., Zang, H. P., Wang, G. M., and Lin, Z. T., 2005, "Research on the Auxiliary Design Sohware Model of Righting Sunken Ship," In: The 2005 Salvage annual Symposium, Chongqing, China, pp. 106-113. (in Chinese)

[21] Deng, Z. T., 2006, Chuanbo Gailun, China communications Press, Beijing, China, pp. 23-25. （in Chinese)

[22] Chen, Z. R., Jin, C. M, and Wang, C. M., 2003, Engineering fluid mechanic(2nd edition), Higher education press, Beijing, China, pp. 107-113. (in Chinese)

[23] Sheng, B. Z., and Liu, Y. Z., 2003, Principle of Ship, Shanghai Jiao Tong University Press. Shanghai, China, pp. 20-23. (in Chinese)

[24] Ma, Z. W. , 1999, "Calculation of Damaged ship on still water," MA.Sc. thesis, Wuhan Transportation University, Wuhan, China. (in Chinese)

[25] Zhang, H. L., 2002, "Engineering of underwater oil recovery and refloated for "Yunhong" ship," In: Proceedings of the 2nd China international rescue and salvage conference, Ningbo, China, pp. 36-38. (in Chinese)

[26] Cong, P. S., and Zhou, X. Q., ““'Jin Ji 7” Salvage,” 2005, China Rescue and Salvage, (11), pp. 16-20. (in Chinese)

[27] Wang, D. N., and Zhou, X. Q., 2009, ““Jiao Zhua 106” Grab Dredger Salvage,” In: The 2009 Salvage annual Symposium, Wuhan, China, pp. 152-154. (in Chinese)

[28] ..., 1974, "US Navy Salvage Report: Suez Canal Salvage Operations in 1974", 20362, Department of the Navy Naval Sea Systems Command, Washington, D. C.

[29] Zhao, M. X., 1995, "Analysis of righting force during salvage of "Changzheng" ship," J. Marine Technology. 2, pp. 16-20. (in Chinese)

[30] Sun, Z. C., Wu, J. C., and Zhang, Y. Q., 2008, "Salvage of Neftegaz 67 with HUA TIAN LONG,” In: Proceedings of the 5nd China international rescue and salvage conference, Dalian, China, pp. 158-162. in Chinese )

$\begin{array}{lll}\text { Submitted: } & 21.08 .2015 & \text { De-wei Pan } \\ \text { Accepted: } & 22.06 .2016 & \text { Cheng-xin Lin, lch_xin@126.com } \\ & & \text { Zhi-jie Liu } \\ & \text { Transportation Equipments and Ocean Engineering College } \\ & \text { Dalian Maritime University } \\ & \text { De-ping Sun } \\ & \text { Marine Engineering College, Dalian Maritime University }\end{array}$

